\title{
Message from the Commonwealth Secretary-General
}

The Universal Periodic Review (UPR) is an unique mechanism, designed to bring benefits to real people in real human rights situations. Peer review is of great value, in that it holds member states to account by setting standards both for themselves and for others.

The UPR operates at different levels: governments, National Human Rights Institutions (NHRIs) and NGOs (non-governmental organisations). The Commonwealth is uniquely placed, with networks in all three.

I warmly commend this publication and encourage its use by all member states taking part in the review process.

We recognise that different Commonwealth countries will have differing needs at different stages of the review process. But everyone should be striving together - even if from very different perspectives and strengths - towards the same goal. Our task is to uphold the values we espouse, as set out in the Trinidad and Tobago Affirmation of Commonwealth Values and Principles, agreed by Commonwealth Heads of Government in Port of Spain, Trinidad \& Tobago in November 2009.

To all our member governments, I confirm that the Commonwealth Secretariat stands ready to support you in the Universal Periodic Review at preparation and follow-up stages, and that its Human Rights Unit (HRU) is at your service.

\section{Kamalesh Sharma}

Commonwealth Secretary-General

London, April 2011 
